\title{
There are Coalitions Everywhere
}

Coalitions and Side Payments in the Committees under the Open Method of Coordination

Nedergaard, Peter

\section{Published in:}

European Societies: The Official Journal of the European Sociological Association

DOI:

$10.1080 / 14616690802326418$

Publication date:

2009

Document version

Early version, also known as pre-print

Citation for published version (APA):

Nedergaard, P. (2009). There are Coalitions Everywhere: Coalitions and Side Payments in the Committees under the Open Method of Coordination. European Societies: The Official Journal of the European Sociological Association, 11(5), 549-671. https://doi.org/10.1080/14616690802326418 


\title{
THERE ARE COALITIONS EVERYWHERE
}

Coalitions and side payments in the committees

under the open method of coordination in the

\author{
European Union
}

\section{Peter Nedergaard}

University of Copenhagen, Department of Political Science, Øster Farimagsgade 5, DK-1353 Copenhagen K, Denmark

ABSTRACT: Do members of the committees under the Open Method of Coordination (OMC) find that there are coalitions of specific member states in these committees? If so, then what kind of side payments hold these coalitions together? For the first time in scholarly literature, and based on an empirical investigation, the findings in this paper document that two opposing coalitions - with the United Kingdom and France as the respective leaders - exist in OMC committees where mutual learning is the raison d'être. In the existing theory on this subject in the EU, it is claimed that consensus decision-making leads to a weakening of coalition-building. All three committees analysed in this paper build on consensus decisionmaking, which is achieved after intensive meetings between all the members. However, it is contended that the 'argumentative contest' working method of the OMC committees leads to more - not less - coalition-building. On the basis of a test, it is also shown that these committees are primarily held together by side payments in the form of 'promises relating to policy among the like-minded'; however, 'payments allied to subsequent decisions' add to the cement of the coalition-building processes stemming from the OMC working method.

Key words: European Union; side-payments; open method of coordination; coalitions; committees

\section{Introduction}

In spite of the voluminous literature on the EU Open Method of Coordination (OMC), no one has hitherto investigated the building of coalitions in the committees comprising the foundation of this influential method of cooperation between the EU member states. 
A number of scholars have previously addressed general questions regarding the coalitions and patterns of cooperation in EU decisionmaking processes in general. Hosli (1996) analysed potential coalitions based on power indices calculated according to the voting power of member states in the Council of Ministers. Beyers and Dierickx (1997) focused on the role of communication networks in informal day-to-day negotiations between officials, finding that 'only the North-South division yielded significant results' (Beyers and Dierickx 1997: 464). Beyers and Dierickx (1998) concluded that nationality is an important factor in establishing relationships in Council working groups. Both papers by Beyers and Dierckx were based on interviews across a broad spectrum of Council working groups, and their aims were to investigate communication networks, not necessarily coalitions.

A study by Kaeding and Selck (2005) focused on the empirical applicability of theories of coalition patterns based on power, interest, ideology and culture in formal EU decision-making: the authors compared the policy preferences of the member states, the European Parliament and the European Commission in relation to 70 legislative proposals, and used voting patterns in the Council of Ministers to map out policy positions and coalitions among the member states. As can be seen, however, Kaeding and Selck (2005: 279) included only hard law instruments with binding legal effects; they did not explicitly include soft law instruments.

Ole Elgström et al. (2001) analysed coalitions in the negotiations among officials in the EU decision-making process on the basis of an extensive survey of Swedish EU committee members. They found a prevalence of coalitions based on policy interests and cultural affinity. The OMC was not, however, examined, and the exclusively Swedish group of respondents was an acknowledged limitation to the research. As the OMC has attained increased salience in EU policy-making, the dynamics of coalition-building within it merit particular attention. Kaeding and Selck (2005: 272) mention a further reason for investigating the subject which, at the more general level, the author of this paper can only concur with: 'Our scholarly understanding of coalition patterns in EU decision-making is, despite its importance, limited'.

This paper will focus on coalition-building in the soft law cooperation of the EU, a previously untouched issue in scholarly literature. It is predicted that coalition-building in soft law areas is likely to differ from that in areas where hard law is the rule of the game. This likely difference primarily stems from two factors.

Firstly, coalition-building in formalised arenas such as the Council of Ministers is more likely to be linked with explicit voting rules where actors are poised to focus on achieving a minimum winning coalition, for instance if qualified majority voting takes place. This is the case even 
though traditional Council committees are also based on consensus. However, this consensus decision-making often takes place in the shadow of the possibility of future qualified majority voting (Nedergaard 2007: 160-74). ${ }^{1,2}$ Conversely, OMC decisions are made by consensus, implying that the coalition patterns will remain less explicit. Whereas the traditional Council committees are charged with the preparation of decisions on directives and regulations in the Council of Ministers (i.e., hard law), the OMC committees are responsible for enhancing mutual learning through recommendations, benchmarking, best practice etc. (i.e., soft law). This also means that coalition formation can be expected to assume different forms within the OMC committees. Hence, coalition-building in this area is likely to be governed by more fluid dynamics due to the lack of firm coalitions behind either qualified majorities or blocking minorities.

Secondly, policy learning is the stated raison d'être of the committees in the OMC area (see Nedergaard 2006). Some scholars reject policy learning as a public logic that serves as a thin veneer over interest-based positions. However, respondents in this survey report policy learning and, over time, political actors tend to adhere to their public logic: reneging on such can be costly in terms of political capital and loss of credibility. The dynamics of coalition-building in the OMC area should thus be considered in connection with policy learning as the overall logic in the committees.

All of the investigated OMC committees are based on consensual decision-making, where recommendations are adopted and sent to the Council of Ministers in one of its various configurations (ministers of economics, employment, and social affairs). ${ }^{3}$ Before consensual decisions are reached, however, an intensive and cumbersome debate transpires in the committee meetings.

In Section 2 of this paper, the usefulness of coalition theories and concepts for analysing the OMC processes will be examined. In Section 3, hypotheses about the dynamics of coalition-building in the OMC committees are established. Section 4 provides an operationalisation of the hypotheses presented in Section 3. Section 5 describes the research methodology, summarises the data and offers some preliminary results. In Section 6, detailed data on the Employment Committee, the Economic

1. I distinguish between consensus and unanimity. Consensus is when all members of a decision-making body passively accept a proposal. Unanimity is when all members of a decision-making body explicitly participate in making a decision through a voting procedure.

2. Cf. Riker (1962: 100). This is, however, not always the empirical outcome as other factors such as 'language, history, and general cultural characteristics' are determinants of EU coalition building in the Council of Ministers (Kaeding and Selck (2005: 282).

3. See footnote 2 above. 
Policy Committee and on the Social Protection Committee is provided. Section 7 considers the origin of coalitions in the OMC committees with regard to the European politico-economic models, thereby offering a soft test of the hypotheses. The conclusion of the article is presented in Section 8 .

\section{Coalition theory and concepts for the analysis of the OMC committees}

In the OMC area, policy learning is the stated raison d'etre of the involved committees (see Nedergaard 2006). Interest- or power-oriented scholars will argue that the stated goals of the OMC only serve to obscure the actual dynamics of the method, such as strategic bargaining. However, an empirical analysis of OMC committees has concluded that: 'Strategic bargaining is not the general mode of interaction in the committees' (Jacobsson and Vifell 2003: 19). The study also found that, in the case of politically sensitive issues, contacts between members aimed at building coalitions in the committees for bargaining take place prior to meetings (ibid.). The interaction between the general modus of mutual learning and bargaining on some particularly contentious issues means that the dynamics of coalition-building in the OMC are worthwhile studying; in this case, however, coalition-building differs from the precise definitions of coalitions in the classical political science literature on winning, losing and blocking coalitions, as in the ground-breaking book of William $\mathrm{H}$. Riker (1962: 255-6).

Moreover, the definition provided by Elgström et al. (2001: 113), where a coalition is 'a set of actors that coordinate their behaviour in order to reach goals they have agreed upon', implies that coordination takes place, which is not always the case in the OMC. Rather, since the dynamics of coalitions in the committees are also characterised by an 'argumentative contest' (Jacobsson and Vifell 2003), a coalition is defined in this paper as a group of actors subscribing to the same position or perceived to share the same position by other actors. This definition is reflected in the data collection.

Nonetheless, the classical concept of leaders and followers is regarded as useful in this paper. In this investigation, actors in a coalition are often referred to with reference to a specific member state acting as leader within that coalition, as will be shown later (see also Riker 1962: 103; Beyers and Dierickx 1998: 307). In addition, the difference in institutional capacity between larger and smaller member states is likely to have an impact on the probability that a given country will emerge as a leader of a coalition (Beyers and Dierickx 1998: 309). 
At the same time, due to the fluid boundary between arguing and bargaining in the OMC committees, especially in connection with the issue of recommendations, actors are always assumed to be in the process of building a potential coalition. Hence, coalitions might also consist of members who have a looser or more marginal connection to them. Consequently, contrary to traditional analyses (Riker 1962), and due to the more fluid dynamics of the OMC processes, analysing coalitions and coalition-building in these committees becomes one and the same thing. This is also reflected in the data collection that this paper is based on (see Section 5). Coalitions in the OMC committees seldom materialise in the same manner as in organs where a voting procedure could potentially take place at some point in the decisionmaking process.

The concept of side payments is another notion from classical coalition theory that is relevant to this paper, as it offers an analytical perspective on the dynamics of coalition-building. While in common usage side payments refer to money, it should be emphasized that in this paper they are intended to denote 'all artefacts and sentences (such as promises on policy) that conceivably have value for members of the body' (Riker 1962: 105). According to Riker (1962: 108-14), the various kinds of side payments in this context include:

1. The threat of reprisal: this type of side payment appears to belong only to so-called police states in which coalition-building does not constitute the main kind of decision-making.

2. Payments of objects, the value of which can be estimated in monetary terms: likewise, these kinds of payments are not relevant for coalition-building in the OMC committees, since decisions here have no immediate budgetary implications.

3. Promises relating to policy among the like-minded: a prospective leader typically starts with a proposed decision. A number of like-minded members then join him/her immediately in support, thereby becoming his/her followers. For these initial like-minded followers, the payment will be the achievement of the proposed decision. This kind of payment might be relevant in some cases in the OMC committees. Hence, one likely logic stemming from coalition-building is that of achieving solidarity among the like-minded.

4. Payments relating to subsequent decisions: if a leader of a coalition concerned with one particular issue can reasonably be expected to play the same role in a number of future resolutions, then he/she can believably offer promises about subsequent decisions. Followers will therefore support the coalition leader in the expectation of future benefits, which in the case of the OMC committees becomes linked to 
the display of best practices. This kind of side payment is also relevant to the OMC committees where the leaders of the coalitions are normally the same (see below).

5. Payments relating to emotional satisfaction: this has nothing to do with the like-mindedness highlighted under category (3). It is something much more irrational, akin to Sigmund Freud's description of leadership as a kind of love affair between each follower and the leader, or similar to Max Weber's concept of 'charisma'. This kind of side payment might be relevant to OMC coalitions. However, they are difficult to investigate using the methodology of this paper; hence, they are not analysed here.

In sum, the side payments analysed in this paper as part of the coalitionbuilding process are either (a) promises related to policy among the likeminded or (b) payments related to subsequent decisions.

In this paper, the specific questions are as follows: Do members of the OMC committees find that there are coalitions of specific member state representatives in the OMC committees? If so, then what kind of side payments hold these coalitions together? Based upon responses to a questionnaire distributed to the members of the three selected EU OMC committees, answers to these two questions are provided in this article.

The analysis will initially focus on the Employment Committee (EMCO) and the Economic Policy Committee (EPC). An evaluation will then be made of the pattern in the Social Protection Committee (SPC). However, it should be noted that analysis of coalitions and coalition-building in the SPC is more difficult due to the poorer quality of available data.

These three committees were originally selected for several reasons: (1) they have several years of experience in the elaborate procedures involved in handling the OMC processes, thus rendering it possible to distinguish possible coalitions; (2) their members have therefore also had the opportunity of familiarising themselves with the detailed positions of other member state representatives; (3) they represent a variety of policy areas, from 'hard core' economics (EPC) through to 'soft' welfare state issues (SPC), with EMCO covering the middle ground; and (4) they represent EU policies springing both directly (employment policy in EMCO) and indirectly (economic and monetary policy in EPC) out of the EU treaty, as well as those that are not embedded in it (social protection policy of the SPC). Admittedly, however, the three committees all serve economic policy in the broad sense of the concept. In short, the selection in this paper follows a similar research design. 


\section{Hypotheses about side payments in OMC committees}

Kaeding and Selck (2005: 273) derived four hypotheses concerning coalitions in EU committees from the two most important approaches to social enquiries, namely rationalism and constructivism:

1. A pomer-based hypothesis: coalitions arise among or with the most powerful actors in terms of voting strength.

2. An interest-based hypothesis: interests form the basis of coalitions, leading them to becoming more or less constant alliances in each particular sector.

3. An ideology-based hypothesis: differences in ideology, such as a leftright dimensions, pro-integrationists versus anti-integrationists etc. lead to coalitions, and a repetition of patterns in different issue areas is therefore predictable. Hence, coalitions can shift over time.

4. A culture-based hypothesis: differences in cultures - the 'north vs. south' dimension being the most frequently mentioned - lead to coalition formation which should therefore be expected to be similar in different issue areas. Furthermore, coalition patterns based on culture are expected to be quite fixed.

The power-based hypothesis is not relevant for this study when interpreted in terms of voting strength. However, the fact that coalitions appear to have a leader or a hegemon is a sign of power. For the purpose of this paper, it is also difficult to distinguish between ideology- and culturebased hypotheses. Instead, the first main hypothesis is that of the 'most similar', which is a combination of Kaeding and Selck's ideology- and culture-based hypotheses.

The second main hypothesis partly draws on 'interest-based' partly on the non-voting factors relevant to 'power-based', and finally on the very nature of the work in the OMC committees. This is termed the 'best practice' hypothesis, predicting that member states form coalitions with member states with the best practice, the best indicators, the best performance etc. in a particular area, because it is in their interests to do so. This hypothesis is also underpinned by a study of the direction of the learning processes in the EU OMC committees, which indicates that members claim to learn from the member states that are the best performers, not from the states that they like the most (Nedergaard 2006).

In conclusion, the two basic hypotheses about coalition formation in the OMC committees are as follows. Coalition formation in OMC committees depends on: (1) the degree to which member states share a similar economic-political background (the 'most similar' hypotheses) and/or (2) which member states can demonstrate 'best practice' (see Nedergaard 
2006). The prediction of the 'most similar' hypothesis is that coalition formation takes place among member states with similar politicocharacteristics. The 'best practice' hypothesis predicts that coalition formation proceeds across a group of member states sharing similar politico-economic characteristics.

These two hypotheses can be linked to two different types of side payments. The logic of achieving solidarity among the like-minded ('promises of policy decisions among the like-minded') can be interpreted as equivalent to the 'most similar' hypothesis, while the logic of offering benefits to the unlike-minded rests on the display of 'best practices' in the learning process; in other words, the unlike-minded join the coalition because they expect to then be able to adopt the best practices on offer and thus to benefit in some way or another. This implies that the 'most similar' hypothesis is a proxy for side payments as 'promises relating to policy among the like-minded', and that the 'best practices' hypothesis is a proxy for side payments as 'payments relating to subsequent decisions'.

\section{Operationalisation of the hypotheses}

In order to progress in investigating which types of side payments are predominant (and with a view towards analysing which EU member states comprise the OMC coalitions), Ebbinghaus' groupings, which are based on the respective similarities and differences between the countries' politico-economic backgrounds (Ebbinghaus 1999), are utilised in this paper. Coalitions in the EU decision-making process are usually categorised along vague (and sometimes inconsistent) north-south lines (e.g., Hosli 1996; Beyers and Diereckx 1998; Elgström et al. 2001; Kaeding and Selck 2005). Ebbinghaus' categorisation is much more clear-cut, in that the groupings are based on politico-economic attributes; they therefore correlate closely to the selected OMC committees which in turn demonstrate similar characteristics (economic, employment and social policy). Furthermore, the advantage of using Ebbinghaus' groupings instead of, for instance, those of Esping-Andersen (1999), is that the former include more European countries. ${ }^{4}$ Most importantly for this

4. This article draws on the Ebbinghaus categorisation of the European countries in four categories, in addition to which a fifth category including the new transition economies has been added. This categorisation is one of many that have been suggested in the literature on varieties of capitalism and types of welfare states. An excellent overview of the different categorisations presented in the literature can be found in Jackson (2002). 
analysis, Ebbinghaus' categorisation is explicitly established in order to analyse differences concerning politico-economic characteristics.

Unfortunately, Ebbinghaus' analysis does not include all the EU member states encompassed in this survey. In this paper, Luxembourg has been added to the group of member states with a Central European politico-economic model, and Malta and Cyprus to those with a Southern European model. Ebbinghaus also does not include the Eastern and Central European member states, with economies in transition, which are in a separate category here (Table 1). Of course, this categorisation of all the new member states (except Malta and Cyprus) is somewhat problematic: they do not share the same politico-economic characteristics. However, as far as the learning processes are concerned, they are all in the same category, as they are all undergoing economic transformation from centrally planned to mixed, European-style market economies. Moreover, the EU has been treating these states in the same way with regard to

\section{TABLE 1. European politico-economic models ${ }^{a}$}

1. The Nordic model

2. The Central European model

3. The Southern European model

4. The Anglo-Saxon model

5. Economies in transition
- Denmark
- Finland
- Sweden
- Austria
- Belgium
- Germany
- The Netherlands
- Luxembourg
- France
- Greece
- Italy
- Portugal
- Spain
- Cyprus
- Malta
- Ireland
- The UK
- Estonia
- Latvia
- Lithuania
- Poland
- Slovak Republic
- Slovenia
- Czech Republic
- Hungary

Source: Ebbinghaus (1999). Countries in italics have been added by the author.

${ }^{a}$ According to Ebbinghaus, France is in an intermediate position between the Central and Southern European models, while The Netherlands occupies an intermediate position between the Nordic, Anglo-Sax on and Central European models. I have categorised France as well as The Netherlands as belonging to the Central European model. 
institution building (e.g., through the Phare programme) and trade relations (e.g., through the Europe agreements).

The five politico-economic models can be characterised as follows:

1. In the Nordic economic model, welfare policies are based on the equal inclusion of all citizens; rules are relatively simple and welfare expenditure is high. This universalist welfare state also combines welfare programmes with predominantly liberal-oriented economic policies, and leaves most of the responsibility for the organisation of the labour market to the social partners.

2. In the Central European model, welfare policies only include everyone to a certain (relatively low) base level, since the selection criteria for the distribution of welfare benefits are based on privileges such as employment and seniority. However, in practice this kind of state is often as expensive to operate as the Nordic type. The conservative Central European model combines welfare policies with relatively interventionist economic policies. This politico-economic model is closest to the 'coordinated market economies' ideal type in the Varieties of Capitalism literature (Hall and Soskice 2001).

3. The Southern European model shares numerous traits with the Central European one. However, it differs by traditionally having an even higher degree of state intervention in the economy, and a relatively low degree of cooperation between the parties in the labour market, which has contributed to the creation of an inflexible labour market. The welfare states in this model emerged relatively late and are not completely developed. Italy is in this category, while France is in an intermediate position between the Central European and Southern European models, since it also shares many traits with the countries in the Central European category (Ebbinghaus 1999: 19).

4. In the Anglo-Saxon model, welfare policies are based on targeting benefits to citizens with special needs. This type of welfare state is relatively cheap. This model combines relevant selective welfare state policies with fiercely liberal-oriented economic policies, and has a very flexible labour market, in which involved parties have limited influence. This politico-economic model corresponds to the liberal market economies' ideal type in the Varieties of Capitalism literature (Hall and Soskice 2001).

5. In addition to the Ebbinghaus groupings, there is a new group of economies in transition consisting of the new member states from Eastern and Central Europe that were all previously subjected to planned economic systems. The grouping consisting of these states is obviously the least solid, since no academic studies of the differences possibly existing between the countries have been carried out. The idea 
behind the joint grouping is that all these new member states are in the midst of a transition from a planned economic regime to a more market-oriented one, and may therefore be expected to have somewhat similar politico-economic backgrounds, as well as facing the same challenges and problems (see above).

If coalition formation takes place predominantly within the various European politico-economic models, it will be concluded in this paper (based on the reasons given in Section 3) that 'promises relating to policy among the like-minded' is the predominant form of side payment in coalition-building in the OMC committees. However, if coalition formation takes place across the various European politico-economic models, the conclusion will be (reasons given in Section 3) that 'payments relating to subsequent decisions' are the predominant type. The testing relating to side payments will be carried out in Section 6 after the presentation of the data in the analysis.

The EPC is the oldest OMC-type committee. Its members discuss and make recommendations on issues concerning the economic policies of the EU member states. It has gained a higher standing since the full implementation of the Economic and Monetary Union in the majority of the member states.

The EMCO is the most well known OMC-type committee with the most developed procedures in terms of annual reporting, detailed recommendations etc. It is also the committee that has spurred most of the significant scientific interest in the EU OMC (see Radaelli 2003; Trubek and Trubek 2003; Jacobsson 2005; Pochet 2005; Zeitlin 2005).

The $S P C$ was established in 2000 in order to discuss and make recommendations pertaining to the social policies of the member states. The working method in the SPC is the same as in EMCO; however, the workload is somewhat smaller and the reporting slightly less exhaustive, even though the frequency of meetings is higher (see below).

In all three OMC committees mentioned above, there is an elected president from one of the member states, chosen from the committee representatives. Generally, however, according to information gathered in connection with this investigation, the presidents are regarded as relatively weak, more like a chairman passing on the word than one setting the agenda. Therefore the role of the president is disregarded in the following analysis. The Commission, on the other hand, is often viewed as a more powerful player than the presidents, sometimes even more so than the strongest member states. At the same time, the Commission is normally not connected to the coalition formation in the analysed committees, and hence its role is also disregarded in this analysis. 
On average, the investigated OMC committee members have 7.3 years experience in their respective fields. SPC tops the scale: its participants have an average of eight years of experience in social protection issues. However, the other two committees lag only a little way behind (EMCO: 7.1 years and EPC: 6.7 years). In this connection, it should be noted that, at the time when the questionnaires were distributed, all the representatives from the new member states had relatively limited experience in the OMC committees, since they had only participated in them for about a year before accession of their states on May 1, 2004 (see next section).

Hence, it is important to take into account the standard deviation associated with the average amount of experience. In all three committees, a small number of very practised participants create the impression of all members having a similar level of practical expertise. In reality, many participants only have between two and three years of service, while only a few have served for a long time. Nevertheless, the working experience of the members is assumed to be sufficient for them to evaluate the question of coalition-building in the committees, even though the low response rate of representatives from the new member states can be attributed to the fact that they were relative newcomers when they responded to the questionnaire (see next section).

\section{Description of data and results}

The analysis in this paper concerns the coalitions as identified by the officials and experts in a selected number of EU OMC committees. The data for the paper stem from a questionnaire distributed to all members of the three selected committees.

The questionnaire was distributed electronically in November and December 2005. From the outset, attempts were made to contact all 270 members and alternates in the three committees, ${ }^{5}$ the members of which are all government officials. Representatives from the committee secretariats present at the meetings are not included in the analysis. In accordance with the definition of coalitions in this paper, committee members were asked to respond to the following questions: (1) 'To what extent is it usual for two or more groups in the committee to disagree during discussions?' and (2) 'Will you name which countries are in the respective groups? - the first group, the second group, etc.'. The committee members could also add comments to these two questions and many did (see Section 3 above).

5. The questionnaire, the collected data etc. is available at the author's homepage www.cbs.dk/staff/pne 
Initially, an informative email with an attached questionnaire was sent to all members. Several email reminders and telephone calls followed. Ultimately, 158 of the 270 members or alternate members completed the questionnaire and returned it, a response rate of 59 percent. Respondents were only asked to complete the questionnaire if they actively participated in the committee work, and the 59 percent are hence likely to represent the most active participants in the committees. ${ }^{6}$ Some did not answer all the questions, and only about half of them answered the two questions about coalitions in the three committees, though with significant differences from committee to committee, with the lowest response rate being that of the SPC (see sections about the individual committees below). All countries were represented among the respondents; however, there was a slight over-representation of Northern European member states and an under-representation of the new member states.

The advantages and disadvantages associated with the use of questionnaires for collecting data are well known. If the response rate is high, it is possible to cover a considerable number of people. Questionnaires covering all members instead of a few in-depth interviews were chosen in order to reach a large number of officials and to ensure that a much higher percentage of opinions from OMC committee members about the structure of coalitions in these committees would be attained. At the same time, it is difficult to ascertain the seriousness of responses and avoid strategic answering. On the other hand, since answers could be given anonymously, these difficulties are not overly significant in this paper. Moreover, this analysis is not about the content of the learning processes. In addition, admittedly, the survey of the OMC committees only uncovers coalitions at a single point in time. Even though they do change over time, it should however be remembered that the coalition members have come up with answers to the questions based on often relatively long experience, cf. Section 4 above.

Table 2 contains some preliminary analysis pointing to a number of tentative conclusions regarding the coalition patterns in the committees.

As illustrated in Table 2, fragmentation into coalitions has occurred to 'some extent' in all committees, ${ }^{7}$ the highest degree of which is seen in EMCO (2.68) and EPC (2.77); the SPC (3.00) scores slightly lower on a scale from 1 (very high fragmentation) to 5 (no fragmentation). The

6. The alternates occasionally participated in the committee work instead of the ordinary members.

7. In the questionnaire, the respondents were asked directly about the fragmentation in the committees, and they were asked to indicate the level of fragmentation (see the questionnaire on my homepage: www.cbs.dk/staff/pne). 
TABLE 2. Coalitions in the EU OMC committees? ${ }^{\mathrm{a}}$

\begin{tabular}{lrccc}
\hline Committees & $N^{b}$ & Mean & S.D. & S.E. of Mean \\
\hline EMCO & 50 & 2.68 & 0.868 & 0.123 \\
EPC & 32 & 3.00 & 0.718 & 0.127 \\
SPC & 56 & 2.52 & 0.894 & 0.119 \\
Total & 138 & 2.69 & 0.861 & 0.073 \\
\hline
\end{tabular}

${ }^{a} 1=a$ high degree of fragmentation in coalitions. $5=$ no fragmentation in coalitions.

${ }^{\mathrm{b}}$ The number of responses deviates somewhat from the number of responses indicated in Table 3 , as not all respondents have answered the question concerning the degree of fragmentation in coalitions.

variation between the SPC vs. EMCO and EPC exceeds the standard of error but is lower than the standard deviation, rendering only tentative conclusions possible. Hence, it would appear that the degree of fragmentation into coalitions is greater in the EMCO and EPC than in the SPC.

Respondents were also asked to place the member states into coalitions if they believed that these exist. Table 3 shows the number of responses given.

An analysis of how respondents place member states in coalitions reveals different patterns for each committee. In the following sections, these are analysed separately for each committee.

\section{Coalition patterns in EMCO, EPC and SPC}

All respondents indicate that either two or three coalitions exist in EMCO. All but two respondents mention the United Kingdom as belonging to one of the coalitions. The frequency with which the UK is identified indicates that it has the strongest position and is hence the leader of the coalition. Additionally, the UK is categorised together with Denmark seven times,

TABLE 3. Which Member States are in which coalitions?

\begin{tabular}{llcc}
\hline & $\begin{array}{c}\text { Number of } \\
\text { members }\end{array}$ & $\begin{array}{c}\text { Number of } \\
\text { Number of } \\
\text { responses to } \\
\text { the questionnaire }\end{array}$ & $\begin{array}{c}\text { Membendents that } \\
\text { have placed } \\
\text { coalitions }\end{array}$ \\
\hline European Employment Committee & Around 90 & 56 & 16 \\
Economic Policy Committee & Around 90 & 64 & 37 \\
Social Protection Committee & Around 90 & 38 & 9 \\
Total & Around 270 & $158(59 \%)$ & $62(23 \% / 39 \%)$ \\
\hline
\end{tabular}


with The Netherlands eight times, and to some extent with Ireland, Sweden and the new member states, which are less consistent followers. None of these followers is categorised as members of opposing coalitions by any respondents (albeit Sweden once).

France is mentioned in connection with another coalition 11 times. Similarly, respondents also group France as the country with the strongest position and enjoying a leading role in the coalition. It is also grouped with Belgium eight times, with Spain five times, with Luxembourg three times, and sometimes with Greece or Portugal. None of these followers is categorised as members of opposing coalitions by any of the respondents.

These two coalitions, with the UK and France as leaders, are mentioned as the two first coalitions by almost all respondents. On the other hand, there seems to be no clear pattern in the countries placed in the third coalition by the five respondents indicating that a third one exists. One mentions Sweden, Finland and Austria, another 'Southern Europe' (i.e., Italy, Spain, Greece and Portugal).

Interestingly, Germany, another major player in the $\mathrm{EU}$, is mentioned only twice, and on both occasions not in coalition with any other committee participant. This would appear to indicate that the German representatives seek to engage in coalition-building to a very limited extent. However, it is also consistent with Germany playing the role as the quintessential compromise-maker, as often pointed out in the scholarly literature on European integration (e.g., Dinan 2005: 74-80). As far as the scant mention of Italy is concerned, one can only repeat what Beyers and Dierickx (1998: 306) found during their research on networks in Council committees: 'Here is a big country ... a long-time member of the EEC and later the EC, which seems relegated to the pack of stragglers and which seems to acquiesce to this status'.

As stated by one respondent who made a written comment: 'UK, Scandinavia/Nordic countries, The Netherlands and most new member states tend to share positions on key issues. France, Belgium, Luxembourg and to an extent Greece/Spain tend not to share the position of the UK, etc.'.

However, two respondents mentioned that coalitions are not static and tend to vary across issue areas.

In their analysis of 70 hard law legislative proposals, Kaeding and Selck (2005: 281) also found two clusters as far as the preference patterns in EU decision-making are concerned. This analysis was based on data from before the 2004 enlargement. The first group included the UK, Sweden, Denmark, Finland, Germany, Austria and The Netherlands. The second encompassed France, Spain, Italy, Greece, Belgium, Portugal and Ireland. The only major difference in the Kaeding and Selck groupings compared to the analysis in this paper concerns the position of Ireland, which has 
TABLE 4. Coalitions in EMCO ${ }^{a}$

\begin{tabular}{lll}
\hline Coalition & \multicolumn{1}{c}{ Primary players } & \multicolumn{1}{c}{ Marginal players } \\
\hline Coalition 1 & $\begin{array}{l}\text { United Kingdom (14), } \\
\text { The Netherlands (8), }\end{array}$ & $\begin{array}{l}\text { Ireland (3), Sweden (2), } \\
\text { 'New Member States' (1) } \\
\text { Denmark (7) }\end{array}$ \\
Coalition 2 & $\begin{array}{l}\text { France (11), Belgium (8), } \\
\text { Spain (5) }\end{array}$ & $\begin{array}{l}\text { Luxembourg (3), } \\
\text { Greece (2), } \\
\text { Possible ad hoc coalition(s) }\end{array}$ \\
& $\begin{array}{l}\text { Sweden (1), Finland (1), } \\
\text { Austria (1), 'Southern }\end{array}$ & \\
& Europe' (2)
\end{tabular}

${ }^{\text {a }}$ The respondents were asked to categorise the coalitions members primary players, secondary players etc. See the questionnaire at www.cbs.dk/staff/pne

traditionally been positioned in the 'southern' group but is located in the UK-led group here (see also Hosli 1996).

Also in the EPC, two opposing coalitions clearly exist. In the first, the UK, Sweden, The Netherlands and Denmark are the key players. They are frequently joined by Finland and on occasion Ireland, Austria, Poland and Slovakia.

In the other, France is consistently mentioned and appears to be the country enjoying the strongest position. Belgium, Luxembourg, Spain, Italy and Germany are frequently highlighted as collaborating with France.

Interestingly, France appears to be an all-important player, as it is not only mentioned as part of a coalition in 33 of 37 responses, but also four times in the coalition constellation 'France' vs. 'most of the others'.

The analysis of the pattern in the SPC is slightly hampered by the fact that only nine of the 38 respondents completing the questionnaire have provided details of the coalitions they claim to exist.

The UK (mentioned by eight), The Netherlands (seven), and Poland (five) are recognised as coalition partners. Marginal players in this

TABLE 5. Coalitions in EPC

\begin{tabular}{lll}
\hline Coalition & \multicolumn{1}{c}{ Primary players } & \multicolumn{1}{c}{ Marginal players } \\
\hline Coalition 1 & United Kingdom (28), & Finland (6), Ireland (3), \\
& Sweden (17), & Austria (1), Poland (1), \\
& The Netherlands (15), & Slovakia (1) \\
Denmark (13). & Belgium (7), Luxembourg \\
Coalition 2 & France (33) & (8), Spain (11), Italy (8), \\
& & Germany (7) \\
Possible ad hoc coalition(s) & $\begin{array}{l}\text { Poland (3), Italy (3) } \\
\text { Slovenia (2), Spain (2), etc. }\end{array}$ \\
\hline
\end{tabular}


coalition are Slovakia (four), Denmark (three), Ireland (two) and Finland (two).

The countries comprising the opposing coalition, France, Belgium and Luxembourg, are all mentioned as members of the same one six times. Other countries are also acknowledged as members of this coalition (i.e., Greece, Finland, Hungary, Spain and Portugal), though not more than once or twice. Finland is the only country mentioned in relation to both.

One of the nine respondents indicated that the three coalitions are 'welfare states' vs. 'more liberal countries' vs. the new member states.

\section{The origin of coalitions in the OMC committees}

The two hypotheses in this paper are the 'most similar' and the 'best practice'. After the individual description of the committees in Sections 6, 7 and 8, the origin of the coalitions in the OMC committees using the European politico-economic models presented in Table 1 will now be evaluated. The result of the analysis is contained in Table 7, where coalition membership is indicated when more than one respondent has pointed out a state as being a member $(\mathrm{C} 1$ is the UK-led coalition, $\mathrm{C} 2$ the French-led coalition).

In the EMCO, all members of Coalition 1 come from either the AngloSaxon or the Nordic model, except for The Netherlands, which occupies an intermediate position between those and the Central European models (see footnote in Table 1). At the same time, the Coalition 2 members come from either the Southern European or Central European model, while France occupies an intermediate position between the two according to Ebbinghaus (see footnote in Table 1).

Coalition 1 in the EPC also stems from either the Anglo-Saxon or the Nordic model, with the exception of The Netherlands, which again retains an intermediate position. Coalition 2 is made up of France as the primary player, and the marginal players ascribe to the Central European and Southern European models.

TABLE 6. Coalitions in SPC

\begin{tabular}{lll}
\hline Coalition & \multicolumn{1}{c}{ Primary players } & \multicolumn{1}{c}{ Marginal players } \\
\hline Coalition 1 & UK (8), Netherlands (7), & $\begin{array}{l}\text { Slovakia (4), Denmark (3), } \\
\text { Ireland (2) and Finland (2) }\end{array}$ \\
Coland (5) & $\begin{array}{l}\text { Greece (2), Finland (2), } \\
\text { France (6), Belgium (6), } \\
\text { Luxembourg (6) }\end{array}$ & $\begin{array}{l}\text { Hungary (2), Spain (1) } \\
\text { and Portugal (1) } \\
\text { None }\end{array}$ \\
Possible ad hoc coalition(s) & None & Non \\
\hline
\end{tabular}


TABLE 7. Coalition members where more than one respondent has pointed to a coalition membership

\begin{tabular}{|c|c|c|c|c|}
\hline $\begin{array}{l}\text { European } \\
\text { politico-economic } \\
\text { models }\end{array}$ & $\begin{array}{l}\text { Member } \\
\text { states }\end{array}$ & $\begin{array}{l}\text { Member of } \\
\text { coalition } 1 \\
\text { (C1) or } 2(C 2) \\
\text { in EMCO }\end{array}$ & $\begin{array}{l}\text { Member of } \\
\text { coalition } \\
1 \text { or } 2 \\
\text { in EPC }\end{array}$ & $\begin{array}{c}\text { Member of } \\
\text { coalition } \\
1 \text { or } 2 \\
\text { in SPC }\end{array}$ \\
\hline \multirow[t]{3}{*}{ 1. The Nordic model } & Denmark & C1 & C1 & \multirow{3}{*}{$\stackrel{\mathrm{C} 1}{\mathrm{C} 1}+\mathrm{C} 2$} \\
\hline & Finland & & & \\
\hline & Sweden & C1 & C1 & \\
\hline \multirow{6}{*}{$\begin{array}{l}\text { 2. The Central European } \\
\text { model }\end{array}$} & Austria & & & \\
\hline & Belgium & $\mathrm{C} 2$ & $\mathrm{C} 2$ & \multirow[t]{2}{*}{$\mathrm{C} 2$} \\
\hline & Germany & & $\mathrm{C} 2$ & \\
\hline & The Netherlands & C1 & C1 & \multirow[t]{2}{*}{ C1 } \\
\hline & Luxembourg & C2 & $\mathrm{C} 2$ & \\
\hline & France & C2 & $\mathrm{C} 2$ & \multirow[t]{7}{*}{$\mathrm{C} 2$} \\
\hline \multirow{6}{*}{$\begin{array}{l}\text { 3. The Southern } \\
\text { European model }\end{array}$} & Greece & $\mathrm{C} 2$ & & \\
\hline & Italy & & $\mathrm{C} 2$ & \\
\hline & Portugal & C2 & & \\
\hline & Spain & $\mathrm{C} 2$ & $\mathrm{C} 2$ & \\
\hline & Cyprus & & & \\
\hline & Malta & & & \\
\hline \multirow{10}{*}{$\begin{array}{l}\text { 4. The Anglo-Saxon } \\
\text { model } \\
\text { 5. Economies in } \\
\text { transition }\end{array}$} & Ireland & C1 & C1 & C1 \\
\hline & The UK & C1 & C1 & \multirow[t]{5}{*}{$\mathrm{C} 1$} \\
\hline & Estonia & C1 & & \\
\hline & Latvia & & & \\
\hline & Lithuania & & & \\
\hline & Poland & & & \\
\hline & Slovak Republic & & & C1 \\
\hline & Slovenia & & & \multirow[t]{2}{*}{ C1 } \\
\hline & Czech Republic & & & \\
\hline & Hungary & & & $\mathrm{C} 2$ \\
\hline
\end{tabular}

In the SPC, members of the French-led coalition are from the Southern European and the Central European models. The UK-led coalition mainly stems from the Anglo-Saxon or Nordic member states, with the exception of the intermediate position of The Netherlands.

In all of the committees, France and the UK generally appear to be leading figures in opposing coalitions. Both appear to recruit members, respectively, from the Southern and Central European politico-economic model and from the Anglo-Saxon and Nordic models, with the exception of The Netherlands (in an intermediate position).

The shape of coalitions in the EMCO and the EPC are very similar, as the UK, The Netherlands and Denmark are central players in both. Some minor differences exist with regard to the marginal players in the coalitions. The same can be said about the coalitions in SPC, but (as mentioned) the number of respondents here is relatively small. However, it 
is not possible to ascertain whether these minor variations are caused by genuine differences or by the small number of respondents having indicated that these countries are members of the coalitions.

This study therefore also confirms the picture outlined in Elgström et al. (2001: 121), in which coalitions based on a north-south distinction occur very often. However, this must be qualified and can be refined. The Northern European member states stem from the Anglo-Saxon and the Nordic models plus The Netherlands, whereas the Southern European member states stem from the Southern European and the Central European models. The new member states are, most often, marginally connected to one of the two groups. Here, however, further investigation is required.

Earlier in the paper in Section 3 on hypotheses about side payments in the OMC committees, it was suggested that if coalition formation proceeds within the various European politico-economic models, it would be concluded that 'promises relating to policy among the like-minded' is the predominant type of side payment in play. However, if coalition formation takes place across the various European politico-economic models, it would be concluded that 'payments relating to subsequent decisions' are predominant. The soft testing of this paper has found that the 'most similar' hypothesis has gained the greatest support and, hence, the first type of side payment mentioned above will be regarded as the most predominant type.

The only exception to that conclusion is The Netherlands, which has from the outset been regarded as a member state in an intermediate position between the various models (see Table 1 above).

The conclusion about coalition formation goes against the tendency as far as learning processes in the OMC are concerned, where member states appear to be learning across politico-economic models according to which member states are the best economic performers (see Nedergaard 2006).

Interestingly, the coalition led by the UK appears to consist of the most economically successful states. They are also the most important countries from a teaching perspective. An interesting road to follow as far as research is concerned is to investigate whether or not the UK-led coalition also gains the upper hand in actual EU decision-making processes.

\section{Conclusion}

The research in this paper concerns an investigation into coalitionbuilding in the three selected committees working according to the open method of coordination in the EU, an area previously neglected in the 
scholarly literature. Traditionally, theories of coalition formation treated this as a game played between parties over Cabinet seats, and they all assumed that parties were office-seeking rather than policy motivated. In addition, even those theories assumed that a winning coalition, if it existed, could form at any point in the policy space (Alt and Alesina 1996: 654-55). Recently, theories of coalition formation have mostly taken the form of formalised spatial models (e.g., Tsebelis 2002).

The purpose of this paper is to take theories of coalition formation into a different terrain, i.e., outside the field of government formation and into areas where policy goals dominate, where actors are civil servants and not politicians, and where coalitions consist of countries and not parties. The research here therefore attempts to further the progress in the construction of a more general theory of coalition formation.

Two questions concerning coalition formation in OMC committees and side payments were raised in this paper.

Based upon a questionnaire distributed to all of the members of the three relevant committees, it was concluded that coalitions certainly do exist in the Employment Committee and in the Economic Policy Committee. Moreover, these committees appear to be overlaid with a pattern in which one coalition is led by the UK and another by France. The pattern of coalitions in the Social Protection Committee is much more diffuse and less pronounced.

The analysis of the specific member state coalitions in the various OMC committees was followed by an evaluation of the dominant side payments which hold these coalitions together. In this context, the investigation attempted to discover whether or not the coalitions have developed, as predicted, from the various European politico-economic models according to a certain pattern. If this was the case, it would be concluded that 'promises relating to policy among the like-minded' is the predominant type of side payment involved. However, if coalitions were found to originate within the various European politico-economic models, it would be concluded that 'promises relating to policy among the like-minded' were of higher importance.

The test showed that 'promises relating to policy among the likeminded' seemed to be the predominant type of side payments in the coalition-building of the OMC committees. This is in keeping with the research into other types of coalition formation, where culture-based coalitions along north-south lines have been found (or hypothesised) to exist (Hosli 1996; Beyers and Diercks 1998; Kaeding and Selck 2005). However, this research has refined these former studies somewhat, and it has been shown that coalition theory can fruitfully be implemented outside its usual field. 
Through this analysis of new forms of international cooperation in the OMC, it is hoped that it has been shown that coalition theory in political science literature has a much broader application than has been previously thought. There has also been an attempt to demonstrate that coalitions sometimes have a much more 'fluid' character than that which is normally analysed in classical coalition theory. In general, political and social research should take more account of member state coalitions. If you can find them in soft modes of governance, they are everywhere.

\section{Acknowledgements}

I wish to acknowledge the contribution of my research assistants in preparing this paper: Kasper Lindskow, Thomas Horn and Henrik Bliddal. Also comments made by Ove K. Pedersen, Ole Helby Petersen and Lars Bo Kaspersen at a work-in-progress seminar at Copenhagen Business School has lifted the quality of the paper. Last but not least, comments from two anonymous referees have made me think things over several times to the benefit of the quality of the paper.

\section{References}

Alt, J. E. and Alesina, A. (1996) 'Political economy: An overview', in R. E. Goodin and H.-D. Klingemann (eds), A Nem Handbook of Political Science, Oxford: Oxford University Press, pp. 645-74.

Beyers, J. and Dierickx, G. (1997) 'Nationality and European negotiations: The working groups of the Council of Ministers', European Fournal of International Relations 3: 435-71.

Beyers, J. and Dierickx, G. (1998) 'The working groups of the council of the European Union: Supranational or intergovernmental negotiations?', Journal of Common Market Studies 36: 289-317.

Ebbinghaus, B. (1999) 'Does a European Social Model exist and can it survive?', in G. Huemer, M. Mesch and F. Traxler (eds), The Role of Employer Associations and Labour Unions in the EMU. Institutional Requirements for European Economic Policies, Aldershot: Ashgate Publishing Ltd, pp. 1-27.

Elgström, O., Bjurulf, B., Johansson, J. and Sannetstedt, A. (2001) 'Coalitions in European Union negotiations', Scandinavian Political Studies 24: 111-28.

Esping-Andersen, G. (1999) Social Foundations of Post-industrial Economies, Oxford: Oxford University Press. 
Hall, P. and Soskice, D. (2001) Varieties of Capitalism. The Institutional Foundation of Comparative Advantage, Oxford: Oxford University Press.

Hosli, M. O. (1996) 'Coalitions and power: Effects of qualified majority voting in the Council of the European Union', fournal of Common Market Studies 34: 255-73.

Jacobsson, K. (2005) 'Trying to reform the "best pupils in the class"? The Open Method of Co-ordination in Sweden and Denmark', in J. Zeitlin, P. Pochet and L. Magnusson (eds), The Open Method of Co-ordination in Action: The European Employment and Social Inclusion Strategies, Brussels: PIE Peter Lang, pp. 107-36.

Jacobsson, K. and Vifell, A. (2003) 'Integration by Deliberation? On the role of committees in the Open Method of Coordination' prepared for the workshop on The Forging of Deliberative Supranationalism in the EU, Florence, 7-8 February.

Kaeding, M. and Selck, T. J. (2005) 'Mapping out political Europe: Coalition patterns in EU decision-making', International Political Science Reviem/Revue Internationale de Science Politique 26: 271-90.

Nedergaard, P. (2005) 'Mutual learning processes of the European employment strategy: Theoretical approaches and methodologies', in T. Bredgaard and F. Larsen (eds), Employment Policy from Different Angles, Copenhagen: DJØF Publishing, pp. 75-95.

Nedergaard, P. (2006) 'Which countries learn from which? A comparative analysis of the direction of mutual learning processes within The Open Method of Co-ordination Committees of the European Union and among the Nordic countries', Cooperation and Conflict 41: 427-47.

Nedergaard, P. (2007) European Union Administration: Legitimacy and Efficiency, Leiden/Boston: Martinus Nijhoff Publ.

Pochet, P. (2005) 'The Open Method of Co-ordination and the construction of social Europe. A historical perspective', in J. Zeitlin, P. Pochet and L. Magnusson (eds), The Open Method of Co-ordination in Action: the European Employment and Social Inclusion Strategies, Brussels: PIE Peter Lang, pp. 37-82.

Riker, W. H. (1962) The Theory of Political Coalitions, New Haven, CT: Yale University Press.

Trubek, D. M. and Trubek, L. G. (2003) Hard and soft law in the construction of social Europe: The role of The Open Method of Coordination, Working Paper of the Governance Project, University of Wisconsin-Madison, Center for European Union Studies, WisconsinMadison, December 2003.

Tsebelis, G. (2002) Veto Players: How Political Institutions Work, Princeton, NJ: Princeton University Press.

Zeitlin, J. (2005) 'Conclusion: The Open Method of Coordination in action. Theoretical promise, empirical realities, reform strategy', in 
J. Zeitlin, P. Pochet and L. Magnusson (eds), The Open Method of Co-ordination in Action: The European Employment and Social Inclusion Strategies, Brussels: PIE Peter Lang.

Peter Nedergaard holds a MSc in Political Science and a PhD in Political Science from the University of Aarhus. He is professor of Comparative Politics at the University of Copenhagen. Before this he was professor at Copenhagen Business School. He has published widely in international journals such as the Journal of Common Market Studies, Journal of European Integration, Public Choice, Scandinavian Political Studies, Public Management Review and Cooperation and Conflict.

Address for correspondence: Professor Peter Nedergaard, University of Copenhagen, Department of Political Science, Øster Farimagsgade 5, DK-1353 Copenhagen K, Denmark.

E-mail: pne@ifs.ku.dk 
Copyright of European Societies is the property of Routledge and its content may not be copied or emailed to multiple sites or posted to a listserv without the copyright holder's express written permission. However, users may print, download, or email articles for individual use. 